\title{
The why, what, when, where and how of sustainability in civil engineering education
}

R.A.Fenner Director, MPhil in Engineering for Sustainable Development, Cambridge University, UK

\author{
H.J.Cruickshank Deputy Director, MPhil in Engineering for Sustainable Development, Cambridge University, UK \\ C. Ainger Visiting Professor, Centre for Sustainable Development, Cambridge University Engineering Department
}

\begin{abstract}
Drawing on 12 years of experience in leading engineering programmes for sustainability in a UK University, the authors take a wide view of the broad range of skills young civil engineers need to deliver the projects they are involved in more effectively. These include dealing with complexity, uncertainty, environmental limits, change, people, trade-offs, other disciplines and whole life costs. In short the paper asks what education do the next generation of civil engineers need to act sustainability in what Schon (1987) memorably called "the swamp" of professional practice? The paper examines the fundamental principles all engineers should be guided by, the optimum points to discuss such issues in the engineers educational formation, how sustainability in the curricula can be linked to civil engineering practice and specific examples of teaching strategies and pedagogies that the authors have found to be effective. A brief review of UK and international best practice in demonstrating the progress that has already been made towards these goals is also presented.
\end{abstract}

Keywords: Education \& training, Sustainability, Social Impact, Environment

\section{Introduction}

Teaching sustainability to civil engineering undergraduate and postgraduate students raises some interesting reactions, with often heard comments such as those below:

"I've just finished the final year elective in Sustainability and I'm disappointed they didn't tell me how to build a sustainable bridge".

"Oh we didn't have specialist electives in our University but I suppose we found that sustainability issues were dealt with at every turn in every subject, as it affects everything we do, and can't be separated out like that".

"Well I'm on a postgraduate course and we took a different route putting everything in a systems context allowing us particularly to deal with the non-technical challenges, including the impact of our engineering on people"

"I've been listening to you three talk and I don't see the point of sustainability, it's woolly and vague and I don't like being told there is no right answer, but I'm quite happy to do my bit to save the environment"

Conversations like this are revealing as they highlight both students expectations and frustrations with what is now an essential part of civil engineering degree programmes, required by the Joint Board of Moderators (JBM) (see below). Let's deconstruct the sentiments expressed above. The first student has the notion that sustainability is something that can be taught like other Newtonian - mechanical subjects, reflecting their own reductionist training and an expectation of something equivalent to a Code of Practice or design checklist. This individual would expect that if these were followed carefully they should automatically result in a sustainable bridge. This very largely misses a key point, which is that sustainable solutions arise out of a better understanding of the context in which the engineering is being delivered, and therefore decisions, designs and delivery systems will be different in every circumstance. Sustainable thinking can't just be reduced to a set of design rules. A key issue for a "bolt on" course for sustainability is not to teach better solutions but to encourage students to ask better questions of the work in which they are involved, and to recognise that sustainability deals with complex, messy problems which have a value-laden perspective for which there may be no appropriate 
simple, technical fix. This is a challenging concept creating uncomfortable feelings in some students and academic staff alike.

The second student seems to have had a better experience, as at their University sustainability education has not been treated as an apparent optional extra, therefore avoiding sending the subliminal message that it is something we can choose to specialise in if we wish, but also ignore quite safely if it is an area we are not naturally drawn to. Instead sustainability is introduced and embedded throughout his course, from Day 1, and discussed in everything from material selection to the life cycle impacts of deep foundations. Whilst this encourages sustainability considerations to become second nature, the emphasis most often lies on environmental sustainability (also reflecting how these issues are often interpreted in industry). Concern for reducing carbon footprints, using less materials, controlling waste etc are all very valid and worthwhile issues to address, but engineering decision-making in reality is more complex when people and the delivery of infrastructure services that are wanted (or not) comes into play. This approach reflects a weakness in the whole sustainability debate which is not to address adequately the human or social dimension in what in reality is a messy socio-economic-technical system.

It is the postgraduate student who seems to have experienced the need to push traditional discipline constrained boundaries: to see engineering activity and the delivery of infrastructure services as a series of interrelated systems, with a rational functional-technical system sitting alongside a relational system which includes organisational structures and social interactions. Given that engineering education MUST teach the basic physical principles properly, and no-one is arguing that these should be supplanted or replaced, then it is at postgraduate Masters level where these fundamental skills might be added to and supplemented, with many of the issues around sustainability being possible to explore effectively in depth. It is engineering graduates and young professional engineers who already have some experience of operating in engineering practice, who can have the freedom to fully engage with difficult problems for which there is simply insufficient time and curriculum space in undergraduate programmes.

And finally we come to the sceptic. These are found at all levels in the profession. Such extreme antagonists to ideas of sustainability are described in McDonough and Braungart's new book "The Upcycle" (2013) as follows: "They test us and everyone else. They are wonderful; they are honest. And once they are personally convinced and get on board, they are very powerful advocates for a sustainable world."

In some ways this scepticism goes to a fear that the traditional role of the engineer is being threatened. No longer can engineers sit above or outside society as technical advocates who "know best" and impose solutions on the rest of the world through a design and defend attitude, but need to take a much more subtle approach of being what has been called honest brokers ( Azapagic et al, 2004). To act in this way requires judging each of several alternative solutions on merit and avoiding pre-determined solutions, simply because they have worked (elsewhere?), sometime in the past (often when the world was operating under a very different set of constraints). In the modern world it is often not the most technically optimum and sophisticated solution that gains the most traction, but perhaps the next best scheme which is acceptable to the widest range of stakeholders and satisfies a wider range of multiple objectives/constraints. Witness the on-going debates around HS2. Learning this is uncomfortable, and may rather glibly be akin to convincing a highway engineer that the best solution to congestion and lack of network capacity may be NOT to build a new road.

These reflections frame the challenges faced by educationalists: a need to address messy problems through a lens of complexity and systems thinking, to recognise the social and non-technical aspects and consequences of an engineer's work, together with the need to give young engineers the confidence to change and challenge orthodox design solutions conceived in previous times when constraints such as climate change and growing resource scarcity were not limiting factors.

How these can be addressed and delivered in civil engineering programmes is the subject of the rest of this paper. 


\section{Why sustainability?}

Answering the question of why sustainability issues should be addressed in civil engineering education has been dealt with by many others and needs little further justification here. The Joint Board of Moderators in their accreditation guidelines for degree programmes makes the case clearly:

"The JBM requires that sustainable development be integrated into existing teaching and learning, and must be pervasive throughout the engineering education programme; a thread of sustainability will therefore run through the programme.

"Engineers should be able to respond to societies' concerns about the impact of human activity on the environment. There is an increasing demand from governments and the public that this environmental concern is placed in the context of achieving the correct balance between environmental, social and economic outcomes within the overarching concept of sustainable development."

Joint Board of Moderators Degree Guidelines Annex C Sustainability (March 2013)

Civil engineers are responsible for delivering much of the critical infrastructure which provide the basic services that allow modern communities and global society to function. However recent events have shown infrastructure systems to be vulnerable to natural events, such as air transport to the Icelandic volcano's ash cloud, the Fukushima nuclear reactor to the Japanese tsunami, or even basic infrastructure and shelter to earthquakes, floods and hurricanes from the Philippines to Haiti and from the USA to East Africa. The most striking impact of Hurricane Sandy in October 2012 was the disruption it caused to New York's critical infrastructure. Conversely, infrastructure itself sometimes can be the cause of the problem, such as the oil spill in the Gulf of Mexico from the Deepwater Horizon platform, or the contribution that the building and operation of energy intensive facilities makes to the accumulation of greenhouse gases in the atmosphere, and global warming.

In many parts of the world infrastructure systems are reaching the end of their intended design life, and often exceeding it. This can lead to unsafe bridges, inadequate flood defences, decay in pipelines, tunnels and airports, or water treatment facilities and power supply systems operating beyond their intended capacity. The ways in which these ageing assets are replaced and refurbished presents an opportunity for the next generation of engineers, educated with sustainability principles at the forefront of their thinking, to provide smarter, more efficient and lower carbon ways of delivering improved services (Ainger and Fenner, 2014).

The infrastructure developed now, if done within the increasing constraints and higher expectations of society, has the potential to provide safety, security, and the adaptations that will be necessary in this century to deal with climate change, increased global population, and how the support systems of the planet are protected. This presents a critical challenge for the future education and training of civil engineers so they are equipped to deliver the radical innovations which will be necessary, not just to help preserve the environment, but to address the real needs of users within tight cost limits and other restraints.

\section{Key Principles - What should be addressed?}

Returning to the JBM, their guidelines stress some important components of what should be covered including the implications of climate change for engineering and the need for carbon critical design and construction, the importance of ethics and environmental justice, and an awareness of resource scarcity - all considered through an interdisciplinary perspective and in the context of impacts on local stakeholders and by adopting a holistic approach to design. This material helps to provide a wider perspective against which to formulate engineering solutions as described by Fenner et al (2006). A knowledge of procedures such as life cycle assessment, environmental management systems and impact assessment tools is also expected. Other "tools" can be usefully added to this list including how to use building rating systems (such as BREEAM and CEEQUAL); ecosystems-services valuation; whole 
life cost accounting; backcasting and scenario planning; multi-criteria decision making and system dynamics.

One of the difficulties with many sustainability discussions however, is how to apply widely accepted principles in day to day practice. In other words how can the new engineering professionals operationalise what they have learnt from an academic environment. To address this directly Ainger and Fenner (2014) have proposed a hierarchy of sustainability principles that can be applied effectively at every stage of the project lifecycle. Engineers understand the concept of physical principles, such as conservation of mass, or Newton's laws of motion. They provide the basic ideas, rules or concepts that need to be kept in mind when solving an engineering problem. Designers also use principles such as "keep it simple, stupid" and "keep the target audience in mind" to guide their thinking. Principles play a key role in setting the context for the choices that have to be made and can be used to guide sustainable decision making at all stages of infrastructure delivery. These sustainability principles are grouped as follows.

First there are 4 absolute principles which are incontrovertible consequences of natural science laws and basic humanity. They should sit alongside the familiar concepts of physical principles when solving an engineering problem. These absolute principles are at the heart of driving sustainability and represent the constraints within which civil engineering activity must be delivered.

The first two of these principles are defined by the boundaries circumscribed by Raworth (2012) in Figure 1. They refer to A1: Work within environmental limits imposed by the 9 planetary boundaries which must be preserved to maintain the essential natural support systems of the planet. Simultaneously A2: Develop minimum socio-economic standards for humanity by helping to provide the social foundation for development in terms of provision of minimum quantities of food, water and energy as well as the right to education, gender and social equality and employment.

The third principle: A3: Consider intergenerational equity simply requires that decisions and actions taken now don't close off options or choices for future generations to live sustainably. It asks civil engineers to take an anticipatory view of the kind of future they wish to create in ways that infrastructure can add benefit, and avoid damage into the future. While the engineered services that society enjoys have often provided buffers against environmental extremes (drought, flood, food security, disease transmission), they sometimes have done so at the cost of a lock-in to expensive technical solutions that do not respond well and cannot be adapted quickly, to the changing and uncertain circumstances which will be faced in this century. Bequeathing assets that lack the necessary resilience to respond to a range of plausible future scenarios is one way in which engineers have already constrained those who come after them. 


\section{Figure 1: Sustainable Development bounded by absolute environmental and social limits (after Raworth 2012)}

The final absolute principle is A4: Conceive solutions as part of a wider complex system. In most civil engineering projects there are links between the technical aspects of transportation, building or water systems and social systems, based on the users of the infrastructure, as manifested in urbanisation, communication and public health, and also the environmental attributes of their natural and urban surroundings. These are intricately linked. There are flows of materials, wealth, energy, labour, waste and information between these systems. Better understanding of these inter-dependancies should reduce the unexpected consequences arising from narrow decisions taken in one infrastructure sector having adverse affects other sectors. As Paul Brown (2008), Executive Vice President of CDM (USA) has observed: "to achieve sustainable urban development we need to do more than improve the efficiency of each of the component parts of our infrastructure - we need to do so at the level of the whole urban system".

These absolute principles translate into a more workable set of operational principles which can help engineers set objectives and guide actions in day-to-day practice. They help establish a distinct way of doing things, partly by recognising issues that traditionally may not have been within the engineer's remit. They are the processes that need to be embraced at each stage of a project and include the following:

- $\quad$ Set targets and measure against environmental limits

- $\quad$ Structure business and projects sustainably

- $\quad$ Set targets and measure for socio-economic goals

- $\quad$ Respect people and human rights

- Plan for the long term

- Consider all life cycle stages

- $\quad$ Open up the problem space (beyond sectoral and discipline boundaries)

- Deal with uncertainty

- $\quad$ Consider integrated need ( encouraging multi functionality of assets)

- Integrate working roles and disciplines

Crucially it is as individuals, acting alone or collectively, that decisions are made that can influence a project outcome to be more sustainable. These represent the often overlooked value base for sustainability, reflecting both an individual's professional and personal ethos. Engineering students should be educated to ask a fundamental question of themselves at every stage of their careers: "Am I 
acting sustainably?". This requires embracing two final individual principles: Learn new skills and challenge orthodoxy and encourage change.

\section{When and where is sustainability important?}

The previous section gives rise to the question of at what point should these ideas be introduced, both in terms of $\mathrm{HE}$ programmes and in stages of project delivery. All students graduating from civil engineering degree programmes need to have an awareness of sustainable development issues, and be able to calculate, for example, the capital and operational carbon embodied in civil engineering projects, understand the ethical choices which have to be made and recognise the environmental and social impacts engineering projects can have. However it is at the level of postgraduate professional practice Masters programmes where there is most freedom to move beyond both curriculum constraints and the traditional emphasis on reductionist thinking which characterises many first degree programmes designed to convey basic engineering science and general principles. It is at the postgraduate level that the application of these principles can be more freely explored against the constraints and complexities represented by the wider issues relating to sustainability.

Fisk and Ahearn (2006) have pointed out that Masters education provides two clear advantages. Students bring with them a maturity and realism of outlook based on their own experiences of working within engineering organisations. They are also likely to take up positions of significant responsibility when completing such courses and be employed as leaders of engineering projects or recruited specifically to change management procedures towards more sustainable approaches. Fisk and Ahearn go on to suggest that such students "are able to challenge assumptions in the classroom rather than discover a disjunction with reality only when they try to apply acquired knowledge in the field".

Despite this apparent desire to see specialisation for some in sustainability thinking and skills, there are opportunities at every stage of project delivery for every well informed and sustainability educated engineer to make a difference. For example at the outset when determining the over-riding business strategy of a project, business models can be chosen which sells the "service" rather than the "product" thus aligning commercial success with sustainability gains. Similarly an adaptive climate change strategy can be adopted with forms of contract and performance measurements aligned to these clear objectives and targets. At the project scoping stage these objectives can be translated into project performance specifications and wider project consequences can be considered across users/customers, local communities and supply chains. Stakeholders should be engaged throughout the project delivery process, including working with regulators to open up the space for innovation. Procurement policy can help provide extra socio-economic benefits of training, jobs and income, and wealth creation to the locality, region or country.

For some the outline design stage may be the first opportunity to influence a project, often by widening the range of options considered to provide real sustainable alternatives which are judged against carefully chosen sustainability criteria and indicators. A danger when arriving at the detailed design stage is that many possible sustainable options have been closed off by earlier decisions, but design-life and re-use options can be explored as well as the benefits of off-site manufacture, and combining the functions of components for resource and energy efficiency, and specifying materials with low embodied carbon and where possible derived from renewable sources. Construction practices can be carefully modified to reduce on-site energy use and waste and to incorporate social/community relations in standard risk management procedures. During operation sustainability performance can be continually monitored, and preventive maintenance carried out to maximise efficiency improvements. Finally, at the end of life the residual material can be dealt with in the following order of preference: directly re-use; dismantle, reclaim and reuse; demolish, reclaim and recycle; demolish and dispose.

These are just some practical everyday steps the individual who is committed to engineering sustainability can achieve. This may be more likely if their education and training has emphasised the techniques and opportunities which can be adopted, in a positive manner rather than a more negative approach which can sometimes portray the growing problems we face as insurmountable. As Mulder et 
al observe (2013) motivating students beyond the fear of global catastrophe is a warning for educators to learn and connecting academic discourse with real life problems can aid that process.

\section{How can sustainability be conveyed (in an educational setting)?}

The final parts of this paper will reflect on ways which can stimulate students on civil engineering programmes to be encouraged to approach the design, construction and operational aspects of the work they will subsequently be involved from both an innovative and change perspective. To do this civil engineering education needs not just to provide the factual basis for evaluating engineering consequences but to develop specific skills, as shown in Table 1.

\begin{tabular}{|l|l|}
\hline Skill & How developed \\
\hline Dealing with complexity & through adopting a systems approach. \\
\hline Dealing with uncertainty & when decision making in the absence of complete information or evidence. \\
\hline Dealing with change & by challenging orthodoxy and envisioning the future. \\
\hline Dealing with other disciplines & through building multi-disciplinary teams. \\
\hline Dealing with environmental limits & through resource efficiency, pollution control and maintaining ecosystem services. \\
\hline Dealing with people & through consultation processes and negotiation to meet society's and individual's needs. \\
\hline Dealing with whole life costs & by considering project externalities and life cycle management. \\
\hline Dealing with trade-offs & by avoiding optimisation around a single variable to create solutions acceptable for all. \\
\hline
\end{tabular}

\section{Table 1: skills required for engineering sustainability}

These skills are not generally appreciated through standard lectures but through a range of complimentary learning activities, such as (but not limited to) the ones described by Cruickshank and Fenner (2012) and summarised below:

\section{Role Plays}

An important aspect to understanding the broader context in which civil engineering solutions must be delivered is to create an emotional attachment to the outcome of the decision. Experiencing something of the (perhaps irrational ) passion displayed when decision stakes are high over an issue relating to a large infrastructure project, for example, can enable students to have more empathy towards stakeholders. Dieleman and Huisingh (2006) argue that using role play based around cases of specific development projects can provide the circumstances to understand the behaviour of people within these contexts and to understand the linkages between certain problems, the behaviour and technologies within these contexts and the problems that result. Most importantly it can encourage contextual thinking and explore issues such as trade-offs, uncertainty, dealing with people and change. An example of such a role play is Puerto Mauricio (van der Wansem et al, 2003) based on a fictional coastal town in which a large and culturally significant parcel of land is about to be sold. Students take on the roles of a variety of stakeholders and try to reach agreement on the development plans for the area. Role plays can also simulate the nature of how decisions are reached over large infrastructure projects through mimicking formal adversarial public enquiries or by consensus building negotiation.

\section{Case Study Field Work}

These are useful for creating a group dynamic in which task sharing is important. They can be used to explore at first hand real dilemmas surrounding existing or planned civil engineering projects. Dieleman and Huisingh (2006) argue that "case studies ... provide the context to understand the particular behaviour of people within these contexts and to understand (comprehend) the linkages between certain problems, the behaviour and technologies within these contexts and the problems that result. It leads to contextual thinking' and provides solutions that are context specific". 
Transport schemes make good case studies, where students can be asked ostensibly to find solutions to the alignment of a new road past a sensitive site such as Stonehenge, but the reality is to expose them to how the complexity of constraints have led in practice to the inability to implement a solution to date, leaving the problem indefinitely unresolved. Such schemes are good examples of messy problem in which solutions must embrace non-technical as well as engineering features. Visits to sites where specific technologies or initiatives have been installed and deployed such as wind farms or solar arrays, sustainable housing developments and urban landscaping can also stimulate discussion around whether such approaches can be scaled up and scaled out. Such activity can show how sustainability principles can be incorporated at a level of operational detail.

\section{Simulation games}

Dieleman and Huisingh (2006) discuss the use of games and simulation models to convey key concepts of sustainable development in relation to Kolb's theory of experiential learning (1984). They argue that using simulation tools, students are able to influence the system, but usually are not able to steer the system in exactly the direction they would like. This means they must try to understand how the system functions and to find ways to make the necessary changes. These kind of system simulations can help the user to understand the functioning of leverage points. These are crucial in the system because by working at these points the entire system can be changed more effectively and efficiently. The use of such models also clearly integrates the important time dimension into the analysis, crucial for an understanding of sustainable development, but often overlooked in teaching strategies. An example of how such simulations can be used to explore the inter-dependancies of coupled resource systems is provided by Bajzelj et al (2014).

Many games exist and some can be used to introduce key concepts such as framing the problem, working within resource limits, or seeing issues from different viewpoints. Readers are referred to the System Thinking Playbook by Sweeney and Meadows (2010) for a comprehensive set of examples. A recently developed board game, Gasuco, developed in Sweden, is designed to stimulate discussion of sustainability topics between groups of 4 students and can be used to introduce topics such as the impacts of climate change, resource depletion or biodiversity loss (Dahlin et al, 2013). This is another example of where students are actively engaged in thinking about the issues, rather than passively absorbing information from more conventional teaching styles.

More extended games that may take a larger part of a day to complete are often built on system dynamics simulations using computer models. Here scenarios are set with the players required to make choices to satisfy an end objective, but their decisions are made with incomplete information on the system response, which is tracked out of view of the players in the background by the computer simulation. The aim is to reach a sustainable solution over a sequence of several rounds. Such a game is Fishbanks (Meadows, 2004) in which fleets of boats of different sizes and owned by a range of operators from families to multi-national corporations seek to optimise their fishing catches and profit whilst staying in business. The diminishing fish stocks are recorded by the computer but not revealed to the participants until the end, providing a good illustration of the tragedy of the commons and offering a rich opportunity to de-brief on many of the sustainability themes discussed earlier.

A modified version of Building Futures, originally developed by RIBA/CABE (2008) as a tool to help communities to think about the future of their neighbourhood, can be used to explore trade-offs in urban planning where various options have designated "points" associated with them and participants must allocate a "spend" of these points against a planning timeline while also meeting some overarching objectives. Analysis of this game allows students to reflect on the need to balance early wins with longterm plans and to address the diverse needs and desires of different members of the community. The aim is to encourage students to look for non-technical as well as the more traditional engineering solutions. 


\section{Change challenges}

These can be undertaken individually by students who identify an issue which affects them, often at a personal level. They undertake to make a positive change over a period of weeks, keeping a log of their progress along the way. The scale and impact of the challenge is of less significance than the experience of undertaking the change and feeling the emotional aspects of the success and frustration encountered. This activity enhances students' ability to appreciate ways in which to instigate a change and make it successful and this can be demonstrated through a follow-on assignment to produce a strategy for change in an organisation or company.

\section{Multi-criteria decision making}

A simple exercise can be constructed around using the Analytical Hierarchy Procedure (for example) in which the object is to choose a sustainable retrofit option to reduce the carbon footprint in a UK domestic building. Criteria to be considered are cost, reduction on greenhouse gas emissions and ease of installation and maintenance. Four alternatives can be evaluated: sealing the building envelope, onsite energy generation, installation of energy efficient appliances and home monitoring with smart performance meters. Students are encouraged to make their own informed judgement to determine the relative pair-wise comparison of criteria with a brief discussion on the rationale used. A single preferred alternative is identified, and the exercise repeated to understand how sensitive the outcome is to the choice of weightings. Such exercises can be extended to more technically based topics such as the process selection for a wastewater treatment plant.

\section{Consultancy projects}

Teams of students can provide a consultancy service for a real external engineering client advising on some sustainability aspects of their operation. The terms of reference for the work should be negotiated and agreed at the outset and might vary considerably but must address a problem facing the organisation from a sustainability perspective and can provide opportunities for local companies to harness the technical skills and innovative ideas of students. Such exercises root the range of possible solutions within real world practicalities and participants often need to develop the honest broker skills referred to earlier in evaluating a series of possible alternative solutions.

\section{Some observations on best practice and progress made}

There are many challenges in introducing sustainability concepts to civil engineering students. Some of the obstacles include limited frames of reference by curriculum designers, misunderstanding of sustainable development boundaries, and a low priority given to the breadth of sustainability issues in relation to narrow subject specialisation favoured by some academics, driven by a commitment to a research agenda. Time constraints on undergraduates driven by heavy workloads and stringent assessment systems can restrict the discussion of sustainability topics. The process of developing appropriate pedagogies for engineering sustainability education is not straightforward. An approach developed in a number of Universities, including TU Delft in the Netherlands (Peet D. and Muldur K.F. , 2002), is to identify champions for sustainability who work with academic colleagues in exploring ways in which sustainability concepts can be interwoven with their own teaching of more traditional civil engineering subjects.

Specific undergraduate programmes exist, for example in Civil Engineering with Sustainability at Brunel University (http://www.brunel.ac.uk/courses/undergraduate/civil-engineering-with-sustainability-beng). Sinnot and Thompson (2012) describe a new degree in Sustainable Civil Engineering in Ireland which makes clear linkages between topics such as design and sustainability, ethics and sustainability by the inclusion of practical examples, problem solving and encouraging decision making. This course also 
introduces modules in Clean Energy Technologies, Sustainable Energy, Construction Technology Systems, Innovative Technology, and Building Energy Performance.

Glendinning et al (2013) describe changes to the content of the Civil Engineering degrees at Newcastle University which are designed to engage "students with the global challenge of engineering a sustainable future for the planet, placing Civil Engineering at the heart of delivering infrastructure and living environments that are sustainable in the 21st century and beyond'. Fenner et al (2005) have described how sustainable development has been embedded in the Engineering Department at Cambridge University reflecting on the actual process of initiating change in an academic institution and where the education balance should lie: between providing access to technological knowledge which can be applied to designing hard solutions, and training engineers to rethink their fundamental approach towards a broader, multiple perspective approach in which problem formulation and context setting play a vital role in reaching consensual solutions with a disparate range of stakeholders.

A wider (non-institutional) view of embedding sustainability into undergraduate civil engineering courses is provided by Oliver Broadbent (2012) who identifies three challenges that engineers must overcome in the field of sustainable design: coping with complexity; values-based decision making, and interdisciplinary working. He also establishes a further key principle by recognising that "sustainability is mindset, not a subject" and that an important element in this kind of education is to take the learners outside their comfort zone. In a related vein Al-Rahaway (2013) sees the missing link in engineering education for sustainable development to be the ethical and moral values of 'managers' and urges universities to proactively and aggressively 'infuse' ethical and moral teachings and values into their respective curricula.

At postgraduate level UK Masters programmes at Cambridge University, Imperial College, Surrey University, Strathclyde University and Heriot Watt University have established taught courses exploring the relationship between engineering and sustainable development. There are several other programmes at other UK Universities which focus on specific issues such as sustainable energy, climate change, urban planning etc.

In the USA Augsburger (2009) identifies 20 American Universities incorporating sustainability into civil engineering programmes based on the "Benchmarking Sustainable Engineering Education: Final Report" (Allen D. et al (2009)) and introduces a metric for assessing the sustainability content in each programme. Bielfeldt (2013) at the University of Colorado reports on the experiences of using different teaching methods to educate engineering students about sustainability, including case studies, software tools, project based-learning (PBL) and project based service learning (PBSL) and assesses whether the methods achieved the targeted learning outcomes. She notes that reflective essays with appropriate prompts can encourage students to consider the value that they place on sustainability both personally and professionally, but observes engineering students are often uncomfortable engaging in these open-ended explorations of their values, feelings, and emotions.

In a study of what engineering students learn on sustainability courses, Segalas et al (2010) found that "most students after taking a course on SD focus on the technological aspects of sustainability, regarding technology as offering solutions to environmental problems". They concluded that there was much less emphasis on the social/institutional aspects of sustainability. Cruickshank and Fenner (2012) looked at 108 institutions in the UK and 31 in North America and were unable to find much evidence of programmes that are actively designed to change the mindset of engineers, concluding that in many cases engineering for sustainable development can be reduced to just the level of a smarter technical fix. A recent paper by Cech (2014) reported a longitudinal survey of 326 engineering students at four US Universities which showed that students' experiences over the course of their undergraduate programmes decreases their interest in the public welfare considerations of engineering work. Cech also notes that even if programmes introduce social justice lectures directly into engineering classrooms, the subtle messages students often receive about the relevance and value of these considerations mean that they may be unlikely to develop critical awareness of public welfare issues. 
A database of 275 global academic programmes in sustainability is provided by the e-Journal Sustainability:Science, Practice \& Policy (see http://sspp.proquest.com/sspp institutions/display/universityprograms).

This covers a wide range of disciplines but it is revealing that only 5 relate specifically to engineering. Academics concerned with the issues raised in this paper meet regularly through an International Conference series in Engineering Education for Sustainable Development where best practice and novel teaching methods are discussed and shared. Proceedings of the $6^{\text {th }}$ Conference, EESD13, can be found at: http://www-eesd13.eng.cam.ac.uk/, however to date civil engineering is not strongly represented in that community.

\section{Conclusions}

So how can the students we eavesdropped on at the beginning best be served? The answer, of course, is that there is not a one size fits all educational approach which will suit all teachers and all students alike. There are many pedagogies which have value and students have different learning styles - so a mix of methods is required. To prescribe otherwise would fail the first test of sustainability thinking: that solutions are context specific and dictated by their location and circumstances.

However, much can be learned by sharing best practice and critically reviewing what has worked and what has not. It is fashionable to cite sustainability as a core pillar claimed to be addressed in many degree programmes. As the typical student comments above reveal, approaches can be mixed and varied. Perhaps the best we can provide as educators is to give the civil engineers of the future the confidence to ask better, smarter questions and to challenge at every stage why they are proceeding in a certain manner. It is as simple as that. As one mature postgraduate student, a former Highway Engineer, remarked when reflecting on the value of embracing sustainable development ideas in engineering practice, she noted it had "provided the full 64 colour set of crayons rather than the eight shades of grey pencil" with which she had been working for most of her professional life.

\section{References}

Schon D.A. (1987) Preparing professional for the demands of practice: the crisis of confidence in professional knowledge. Ch.1 Educating the Reflective Practitioner: Towards a New Design for Teaching and learning in the Professions pp 376, Jossey-Bass Publishers, San Francisco.

McDonough W., Braungart M (2013) The Upcycle - Beyond Sustainability Designing for Abundance. Tantor Media Inc. ISBN-10: 1452662312

Azapagic A, Clift R. and Perdan S (2004) Sustainable Development in Practice - Case Studies forEngineers and Scientists,. John Wiley, New York

Joint Board of Moderators Degree Guidelines Annex C Sustainability (March 2103) (available at: http://www.jbm.org.uk/uploads/JBM123 AnnexCSustainability.doc2013.pdf )

Ainger C., Fenner R.A. (2014) Sustainable Infrastructure - Principles into Practice. ICE Publishing ISBN 978-0-7277-5754-8

Fenner R.A., Ainger C.A., Cruickshank H.J., Guthrie P. (2006) Widening horizons for engineers: addressing the complexity of Sustainable Development Proceedings of the Institution of Civil Engineers, Engineering Sustainability Journal , Volume 159 ES4 pp 145-154

Raworth K (2012) A Safe and Just Space for Humanity: Can We Live Within the Doughnut? Oxfam, Oxford.

Brown P (2008) Cities of the Future. Keynote address, IWA World Water Congress, Vienna. 
Fisk, D.J. and Ahearn, A. (2006), "Creating policy analysis skills in postgraduate engineering for sustainable development", Journal of Cleaner Production, Vol. 14, pp. 946-51.

Mulder K.F., Ferrer-Balas D., Segalas-Coral J., Kordas O., Nikiforovich E., Pereverza K., (2013) Beyond the fear of catastrophe. Motivating students and lecturers for Education in Sustainable Development. Proceedings of the 6th International Conference in Engineering Education for Sustainable Development , Cambridge University UK 22-25 September 2013 (available at: http://wwweesd13.eng.cam.ac.uk/proceedings )

Cruickshank H.J. Fenner R.A. (2012) Exploring key sustainable development themes through learning activities International Journal of Sustainability in Higher Education, Vol. 13 Iss: 3 pp. $249-262$

Dieleman, H. and Huisingh, D. (2006), Games by which to learn and teach about sustainable development: exploring the relevance of games and experiential learning for sustainability. Journal of Cleaner Production, Vol. 14, pp. 837-47.

Bajzelj, B. Fenner R.A., Curmi E., Richards K. (2014) Using a resource-nexus research model in teaching. International Journal of Sustainability in Higher Education (in press).

van der Wansem, M., Tracy Dyke, T. and Susskind, L. (2003), Puerto Mauricio Development Conflict Simulation, Consensus Building Institute and Vereniging Natuurmonumenten, Cambridge, MA.

Sweeney D, Meadows D (2010) The Systems Thinking Playbook: Exercises to Stretch and Build Learning and Systems Thinking Capabilities Chelsea Green Publishing ISBN-10: 1603582584

Dahlin J-E., Larson P., Erlich C. (2013) The use of board games in engineering education for the purpose of stimulating peer participation in lecture theatre discussions. Proceedings of the 6th International Conference in Engineering Education for Sustainable Development , Cambridge University UK 22-25 September 2013 (available at: http://wwweesd13.eng.cam.ac.uk/proceedings )

Meadows, D. (2004), Game, The Laboratory for Interactive Learning, FishBanks Ltd, Durham, NH.

RIBA/CABE (2008), Building Futures Game: Developing Shared Visions for Neighbourhoods, Created and developed by AOC, available at: www.theaoc.co.uk

Peet D.J., Mulder K.F. (2002) Integrating SD into engineering courses that are not specifically SD targeted: The DRAIA method. EESD 2002

Sinnot D, Thomas K (2012) Integrating Sustainability into Civil Engineering Education: Curriculum Development \& Implementation 4th International Symposium for Engineering Education, 2012, The University of Sheffield, July 2012, UK

Glendinning S., O'Connell E., Mace A., Hall J., (2013) Embedding sustainability into the Civil Engineering Curriculum - a design based approach Proceedings of the 6th International Conference in Engineering Education for Sustainable Development, Cambridge University UK 22-25 September 2013 (available at: http://wwweesd13.eng.cam.ac.uk/proceedings )

Fenner R.A., Ainger C., Cruickshank H., Guthrie P. (2005) "Embedding Sustainable Development into Cambridge University Engineering Department" International Journal of Sustainability in Higher Education Vol 6, No. 3, pp 1467-6370.

Broadbent O. (2012) Embedding sustainability in undergraduate civil engineering courses - A Practical guide. Think Up (the educational arm of Useful Simple. Morley House, 320 Regent Street London, W1B 3BB). 
Al-Rahaway K.H. (2013) Engineering Education and Sustainable Development: The Missing Link. Procedia - Social and Behavioural Sciences. Volume 10222 November 2013, Pages 392-401 6th International Forum on Engineering Education (IFEE 2012)

Augsburger K (2009) Undergraduate Civil Engineering Sustainability Education Metric(UCESEM) Benchmarking Civil Engineering Program Performance. Virginia Tech Myers-Lawson School of Construction. Unpublished Masters Thesis

Allen, D., Allenby, B., Bridges, M., Crittenden, J., Davidson, C., Hendrickson, C., Matthews, S., Murphy, C., and Pijawka, D. (2009). "Benchmarking Sustainable Engineering Education: Final Report." University of Texas at Austin, Carnegie Mellon University, Arizona State University.

Bielefeld A. R (2013) Pedagogies to Achieve Sustainability Learning Outcomes in Civil and Environmental Engineering Students Sustainability 2013, 5, 4479-4501; doi:10.3390/su5104479

Segalas, J., Ferrer-Balas, D. and Mulder, K.F. (2010), "What do engineering students learn in sustainability courses? The effect of the pedagogical approach", Journal of Cleaner Production, Vol. 18, pp. 275-84.

Cech E. (2014) Culture of Disengagement in Engineering Education. Science, Technology and Human Values Vol 39 January 2014 pp42-72 ( first published on-line on September 13, 2013 doi:10/1177/0162243913504305 


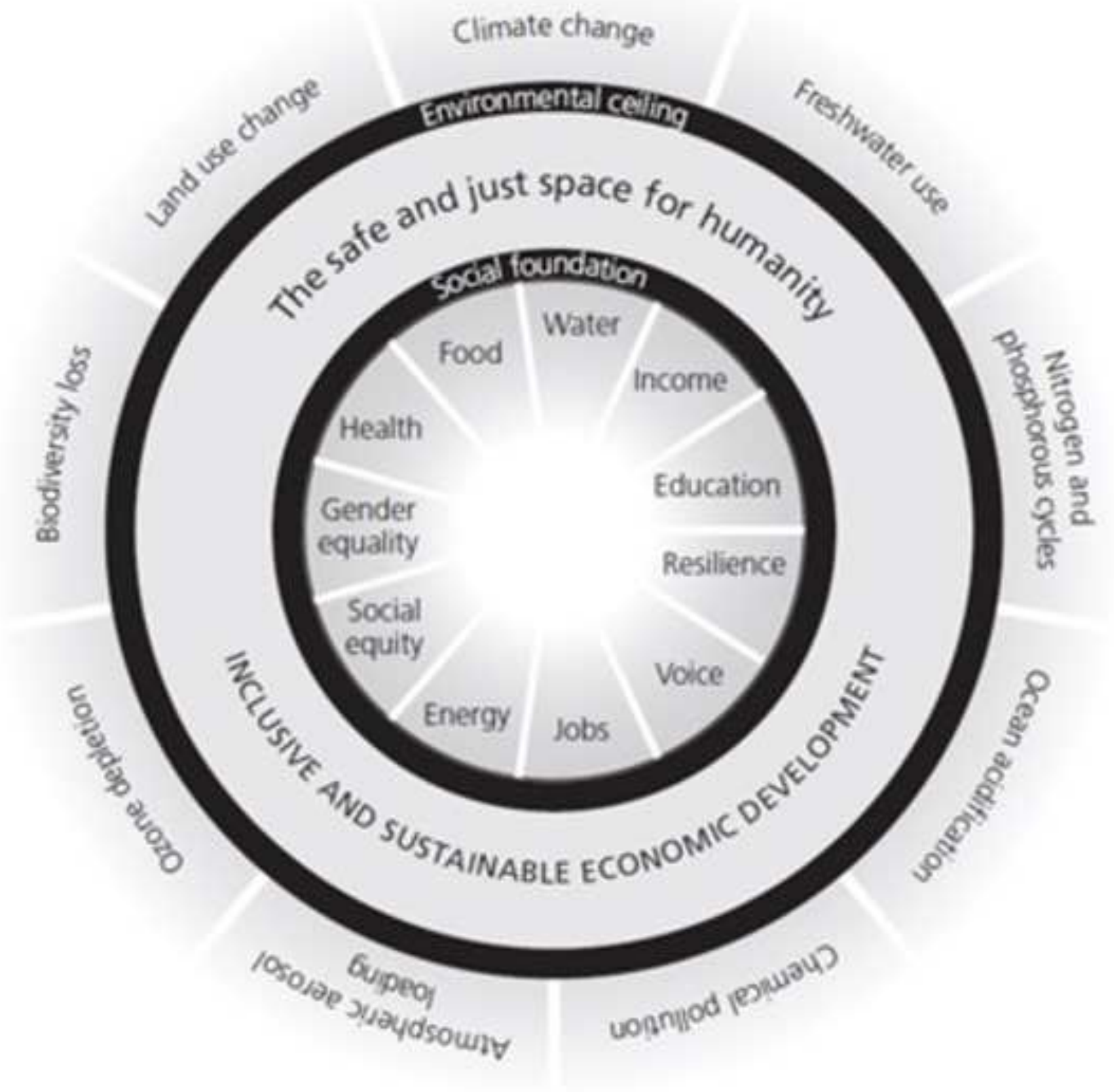


The why, what, when, where and how of sustainability in civil engineering education

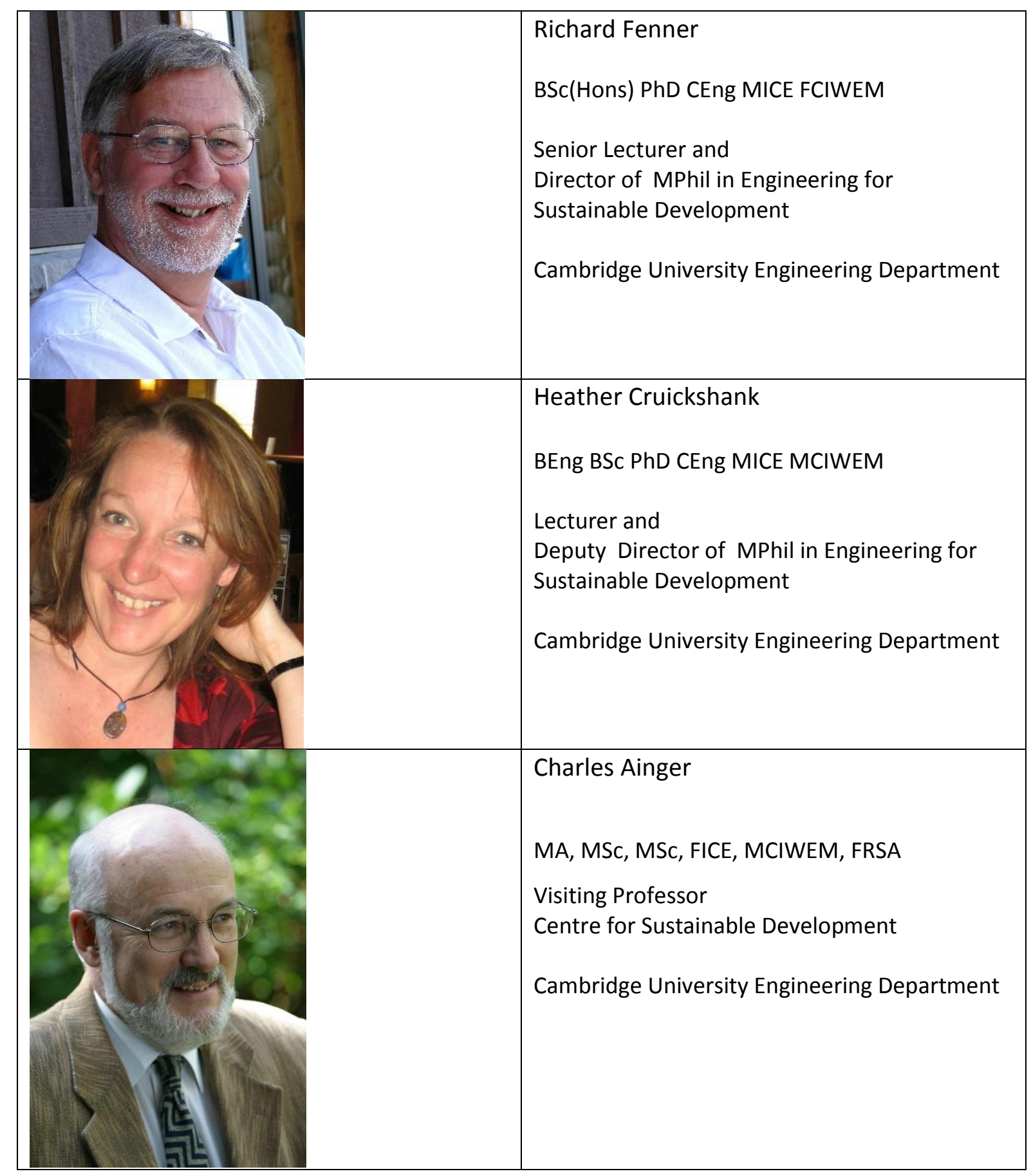


Captions:

Figures:

Figure 1: Sustainable Development bounded by absolute environmental and social limits (after Raworth 2012)

( Note : image supplied as a separate jpeg file.

Image taken from page 11 of Sustainable Infrastructure: Principles Into Practice (2014) by Charles Ainger and Richard Fenner , ICE Publishing. ICE Publishing already holds a copyright agreement for the use of this Figure.

\section{Tables:}

Table 1: skills required for engineering sustainability

An editable version of the Tables is provided below:

\begin{tabular}{|l|l|}
\hline Skill & How developed \\
\hline Dealing with complexity & through adopting a systems approach. \\
\hline Dealing with uncertainty & when decision making in the absence of complete information or evidence. \\
\hline Dealing with change & by challenging orthodoxy and envisioning the future. \\
\hline Dealing with other disciplines & through building multi-disciplinary teams. \\
\hline Dealing with environmental limits & through resource efficiency, pollution control and maintaining ecosystem services. \\
\hline Dealing with people & through consultation processes and negotiation to meet society's and individual's needs. \\
\hline Dealing with whole life costs & by considering project externalities and life cycle management. \\
\hline Dealing with trade-offs & by avoiding optimisation around a single variable to create solutions acceptable for all. \\
\hline
\end{tabular}

